\title{
Partially Reduced Graphene Oxide Modified with Polyacrylonitrile for the Removal of $\mathrm{Sm}^{3+}$ from Water
}

\author{
Khadijah Mohammedsaleh Katubi ${ }^{1}$ (D), Fatimah Mohammed Alzahrani ${ }^{1, *(D)}$, Norah Salem Alsaiari ${ }^{1, *}$, \\ Abdelfattah Amari ${ }^{2,3}$, Faouzi Ben Rebah ${ }^{4,5, *(\mathbb{D})}$ and Mohamed A Tahoon 4,6 (D)
}

1 Chemistry Department, College of Science, Princess Nourah bint Abdulrahman University, Riyadh 11671, Saudi Arabia; kmkatubi@pnu.edu.sa

2 Department of Chemical Engineering, College of Engineering, King Khalid University, P.O. Box 9004, Abha 61413, Saudi Arabia; abdelfattah.amari@enig.rnu.tn

3 Research Laboratory of Energy and Environment, Chemical Engineering Department, National School of Engineers, 9Gabes University, Gabes 6072, Tunisia

4 Department of Chemistry, College of Science, King Khalid University, P.O. Box 9004, Abha 61413, Saudi Arabia; tahooon_87@yahoo.com

5 Higher Institute of Biotechnology of Sfax (ISBS), Sfax University, P.O. Box 263, Sfax 3000, Tunisia

6 Chemistry Department, Faculty of Science, Mansoura University, Mansoura 35516, Egypt

* Correspondence: fmalzahrani@pnu.edu.sa (F.M.A.); nsalsaiari@pnu.edu.sa (N.S.A.); benrebahf@yahoo.fr (F.B.R.)

check for updates

Citation: Katubi, K.M.; Alzahrani, F.M.; Alsaiari, N.S.; Amari, A.; Rebah, F.B.; Tahoon, M.A. Partially Reduced Graphene Oxide Modified with Polyacrylonitrile for the Removal of $\mathrm{Sm}^{3+}$ from Water. Processes 2021, 9 , 818. https://doi.org/10.3390/ pr9050818

Academic Editor: Katherine M E. Stewart

Received: 4 April 2021

Accepted: 4 May 2021

Published: 8 May 2021

Publisher's Note: MDPI stays neutra with regard to jurisdictional claims in published maps and institutional affiliations.

Copyright: (c) 2021 by the authors. Licensee MDPI, Basel, Switzerland. This article is an open access article distributed under the terms and conditions of the Creative Commons Attribution (CC BY) license (https:// creativecommons.org/licenses/by/ $4.0 /)$

\begin{abstract}
An in situ emulsion polymerization method was used for the synthesis of polyacrylonitrile nanoparticles amino-functionalized partially reduced graphene oxide (PAN-PRGO). After that, hydrolyzed polyacrylonitrile nanoparticles amino-functionalized partially reduced graphene oxide (HPAN-PRGO) nanocomposite was achieved by the modification of nitrile groups of the composite polymer chains to carboxylic groups, aminoethylene diamine, and amidoxime functional groups through partial hydrolysis using a basic solution of sodium hydroxide for $20 \mathrm{~min}$. Different synthesized materials were characterized and compared using well-known techniques including transmission electron microscope (TEM), scanning electron microscope (SEM), Fourier-transform infrared spectroscopy (FT-IR), Raman spectra, and X-ray diffraction (XRD). The nanocomposite was structured through the interaction between acrylonitrile's (AN) nitrile groups and amino-functionalized graphene oxide nanosheets' amino groups to successfully graft polyacrylonitrile over the surface of functionalized nanosheets as approved by characterization techniques. The synthesized composite was examined for the removal of samarium ions $\left(\mathrm{Sm}^{3+}\right)$ from water. Different experimental conditions including $\mathrm{pH}$, contact time, initial concentration, and adsorbent dose were investigated to determine the optimum conditions for the metal capture from water. The optimum conditions were found to be a contact time of $15 \mathrm{~min}, \mathrm{pH}$ 6, and $0.01 \mathrm{~g}$ of adsorbent dosage. The experimental results found, in a good agreement with the Langmuir isotherm model, the maximum adsorption capacity of $\mathrm{Sm}^{3+}$ uptake was equal to $357 \mathrm{mg} / \mathrm{g}$. A regeneration and reusability study of synthesized composite up to six cycles indicated the ability to use HPAN-PRGO nanocomposite several times for $\mathrm{Sm}^{3+}$ uptake. The obtained results prove that this polymer-based composite is a promising adsorbent for water treatment that must be studied for additional pollutants removal in the future.
\end{abstract}

Keywords: adsorption; polymers; samarium ions; nanomaterials; water treatment

\section{Introduction}

Recently, one of the most worldwide problems is water pollution with different contaminants [1-4]. Lanthanide elements are considered one of these harmful contaminants that have increased in water due to their universal demand as significant innovation basic elements in various applications [5]. For instance, optical glasses, catalysts, steel, and ceramics industrial applications utilize lanthanides 17 elements due to their exceptional 
chemical and physical properties [6]. Unfortunately, due to their bioaccumulation, propensity, and toxicity, unsustainable quantities of these elements are getting into water sources and food chains, causing harmful effects on human health, especially in the vicinity of mines and refineries [7]. For example, the exposition, swallowing, or inhalation of toxic samarium soluble salts can irritate the respiratory tract as well as the eyes and skin [8]. As a result, the removal of $\mathrm{Sm}^{3+}$ from water has been a top priority. Several published studies on the removal of Sm (III) by various adsorbents and biosorbents were identified based on the literature [9-12]. In terms of economy, high-quality products, reliability, performance, versatility, and fabrication, the adsorption-based technique has been widely regarded as the most durable and promising of all existing water treatment techniques [13-16]. Until today, polystyrene, clays, zeolites, and carbon nanomaterials have also been used as adsorbents in water treatment. However, due to some drawbacks, such as nonbiodegradability and poor adsorption capability, some of these adsorbents are not widely used [17]. It is necessary to go through a chemical modification process to increase the ability to recover from treated water, dissolve in acidic media, avoid swelling, and improve adsorption efficiency [18]. The coordination of metal ions with these adsorbents efficiently depends on their surfaces functional groups, such as amidoxime, amino, hydrazine, and imidazole groups that have chelation properties toward target toxic metals [19-21]. Water purification has been achieved using aliphatic polymers with nitrogen functional groups, but their surface area is limited. Though, the polymeric composites of carbon and carbon-based materials have shown very effective adsorption of toxic ions from water/wastewater. Amongst all carbonbased materials, graphene oxide (GO) is a 2-dimensional single thick graphitic carbon atom that can covalently bond to other groups due to the existence of functional groups (reactive oxygen) on its top [22]. Graphene has excellent tailorable functionalities, a large active area, and electrical, mechanical, and thermal properties [23]. Graphene functionalization with polymers containing chelating groups has received a lot of interest in recent years as a way to improve graphene's adsorption capacity. Polypyrrole functional groups have been utilized for the modification of reduced graphene oxide to capture $\mathrm{Hg}^{+2}$ ions from water with high selectivity and capacity [24]. Exceptional physiochemical stability can be achieved via covalently linked hybrid structure. In the current study, polymer-grafted reduced GO (rGO) hybrids were synthesized. Polyacrylonitrile (PAN)-grafted ethylene diamine partially reduced $\mathrm{GO}\left(\mathrm{GO}-\mathrm{NH}_{2}\right)$ was synthesized as a novel promising hybrid nanomaterial. The excellent physical properties of polyacrylonitrile, such as high chemical resistance and harness, beside its low cost, simple synthesis, good environment stability, and non-toxicity, encouraged us to use this polymer in the fabrication of this nanocomposite. Additionally, the polyacrylonitrile affinity toward toxic species can be improved via the simple chemical modification of its suspended nitrile $(\mathrm{CN})$ functional groups to amidoxime (AO) groups [25]. Polyacrylonitrile's non-toxicity and high stability, besides the partially reduced graphene oxide's large surface area, had driven the synthesis of PAN-partially reduced graphene oxide (PAN-PRGO) nanocomposite for the uptake of samarium ions $\left(\mathrm{Sm}^{3+}\right)$ from water. Herein, the surface of functionalized GO nanosheets were grafted covalently with PAN nanoparticles. PAN-PRGO highly covalently attached nanocomposite was synthesized by the emulsion polymerization of acrylonitrile (AN) with ethylene diamine functionalized graphene oxide (GO), in which surface free amino groups of functionalized GO reacted with the nitrile group of AN for the covalent attachment. This step was followed by formation of carboxylate, amidoxime, and amide groups over the nanocomposite surface by partial hydrolysis of free nitrile groups using $\mathrm{NaOH}$ to enhance the chelation and adsorption properties of the nanocomposite toward $\mathrm{Sm}^{3+}$ ions.

\section{Materials and Methods}

\subsection{Chemicals}

Samarium (III) nitrate hexahydrate $\left(\mathrm{Sm}\left(\mathrm{NO}_{3}\right){ }_{6} \mathrm{H}_{2} \mathrm{O}, 99.9 \%\right)$, ethylene diamine tetraacetic acid (EDTA, 98\%), azo-bis-isobutyronitrile (98\%), sodium dodecyl sulfate (SDS) (99\%), ethylene diamine (99\%), acrylonitrile (99\%), and graphite flakes $(99.9 \%)$ were supplied from 
Sigma-Aldrich and used as received without any purification. In all experiments, the used water was deionized water.

\subsection{PAN-PRGO Nanocomposite Synthesis}

Improved Hummer's method [26] was used for the synthesis of functionalized graphene oxide $\left(\mathrm{NH}_{2}-\mathrm{GO}\right)$. A three-necked round-bottomed flask was used to mix $121 \mathrm{~mL}$ distilled $\mathrm{H}_{2} \mathrm{O}$ with $0.42 \mathrm{~g}$ SDS and $0.52 \mathrm{~g}$ of $\mathrm{NH}_{2}-\mathrm{GO}$. The micelles were produced after a half-hour of stirring and sonication. After that, $70{ }^{\circ} \mathrm{C}$ was adjusted to heat the suspension solution and kept at the same temperature. Then, 2, 2'-azobisisobutyronitrile $(0.151 \mathrm{~g}$ dissolved in $1.5 \mathrm{~mL} \mathrm{~N}, \mathrm{~N}$-Dimethylformamide) was added to the suspension. Acrylonitrile as a monomer $(11 \mathrm{~mL})$ was injected after $16 \mathrm{~min}$. The reaction was then permitted to proceed with continuous stirring and nitrogen atmosphere for $5 \mathrm{~h}$. Lastly, the synthesized PAN-PRGO nanocomposite was collected by centrifugation and washed several times with water and ethyl alcohol to eliminate excess unreacted acrylonitrile, then heated at $70{ }^{\circ} \mathrm{C}$ overnight for dryness. For the synthesis of hydrolyzed polyacrylonitrile/partially reduced graphene oxide nanocomposite (HPAN-PRGO) and hydrolyzed polyacrylonitrile nanoparticles (HPAN), synthesized according to the literature [27], $\mathrm{NaOH}(4 \%, 4 \mathrm{~mL})$ was added to $0.22 \mathrm{~g}$ of PAN-PRGO or PAN nanoparticles then refluxed for $25 \mathrm{~min}$ at $70{ }^{\circ} \mathrm{C}$. Lastly, the $\mathrm{HCl}$ and $\mathrm{H}_{2} \mathrm{O}$ were used to wash the filtered mixture to achieve $\mathrm{pH} 7.5$, after which it was dried at $70{ }^{\circ} \mathrm{C}$ under vacuum.

\subsection{Materials Characterization}

The synthesized materials, including HPAN-PRGO, HPAN, GO-NH ${ }_{2}$, and GO, were characterized using different techniques. Fourier-transform infrared spectroscopy (FT-IR6100 Jasco, Tokyo, Japan) was used to perform FT-IR spectra in the range of $400-4000 \mathrm{~cm}^{-1}$ at room temperature and collected at a resolution of $4 \mathrm{~cm}^{-1}$. X-ray diffractometer (XRD, X'Pert Pro, PANanalytical, Almelo, The Netherlands) was used to measure XRD using $\mathrm{Cu}$ Ka radiation $(\lambda=1.5406 \AA)$ operated at $45 \mathrm{kV}$. The diffraction intensities were recorded over the $2 \theta$ ranging from $5^{\circ}$ to $90^{\circ}$ with the constant scanning rate of $1^{\circ} \mathrm{min}^{-1}$. The morphology and size of different materials were determined using a scanning electron microscope (SEM, Quanta FEG 250, Eindhoven, The Netherlands) and a transmission electron microscope (TEM, JEOL JEM-2100 Plus, Hillsboro, USA), respectively, operated at $200 \mathrm{KV}$. The Raman spectra were investigated with a $532 \mathrm{~nm}$ laser beam using a Raman spectrometer (Horiba Inc., Michigan, USA).

\section{4. $\mathrm{Sm}^{3+}$ Adsorption Experiments}

Batch adsorption experiments were used for the study of the adsorption capacities of synthesized materials toward $\mathrm{Sm}^{3+}$ removal from water, with the investigation of the effect of different factors on the adsorption process including contact time, initial concentration of $\mathrm{Sm}^{3+}$, adsorbent dose, and $\mathrm{pH}$ value. During the study of initial concentration effect, $30 \mathrm{~mL}$ of $\mathrm{Sm}^{3+}$ ions in acetate buffer with a concentration range from 10 to $300 \mathrm{mg} / \mathrm{L}$ was mixed with $0.01 \mathrm{~g}$ of adsorbent and shaken for $30 \mathrm{~min}$, then filtered and analyzed for the presence of $\mathrm{Sm}^{3+}$ ions using atomic absorption spectrometry. The $\mathrm{pH}$ effect on $\mathrm{Sm}^{3+}$ adsorption was also investigated in the range of 2 to 8 adjusted using $\mathrm{HCl}$ and $\mathrm{NaOH}$ by mixing $0.01 \mathrm{~g}$ of adsorbent with $30 \mathrm{~mL}$ of $100 \mathrm{mg} / \mathrm{L} \mathrm{Sm}^{3+}$ solution. The solution was shaken for one hour, then filtered and analyzed. To determine the dosage effect on $\mathrm{Sm}^{3+}$ adsorption, $30 \mathrm{~mL}$ of $100 \mathrm{mg} / \mathrm{L}$ of $\mathrm{Sm}^{3+}$ solution was mixed with different masses of adsorbent in the range of 0.001 to $0.05 \mathrm{~g}$ with continuous shaking for $30 \mathrm{~min}$, followed by filtration and analyzing. To study the adsorption kinetics, $30 \mathrm{~mL}$ of $100 \mathrm{mg} / \mathrm{L}$ of $\mathrm{Sm}^{3+}$ solution was mixed with $0.01 \mathrm{~g}$ of adsorbent at different times of adsorption in the range of 0.5 to $60 \mathrm{~min}$. Additionally, the adsorption isotherm of $\mathrm{Sm}^{3+}$ ions was studied by mixing $0.01 \mathrm{~g}$ of adsorbent with $30 \mathrm{~mL}$ of $\mathrm{Sm}^{3+}$ ions in the concentration range of 100 to $1500 \mathrm{mg} / \mathrm{L}$ with shaking for $30 \mathrm{~min}$, followed by filtration and analyzing. Furthermore, the reusability of HPAN-PRGO for the removal of $\mathrm{Sm}^{3+}$ ions was studied up to six cycles. After each adsorption cycle the adsorbent was 
filtered and the adsorbed ions were desorbed by washing with $2 \mathrm{M} \mathrm{HCl}$, buffer solution, and distilled water, followed by drying at $45^{\circ} \mathrm{C}$ to be used in the next cycle. All previous experiments were performed in triplicate.

\section{Results and Discussions}

\subsection{Materials Characterization}

The synthesized materials were characterized using different techniques, as discussed in this section. For the morphology characterization of HPAN-PRGO, PAN-PRGO, HPAN, PAN, GO, and GO-NH ${ }_{2}$, SEM and TEM images are shown in Figures 1 and 2. A smooth surface with several folds of GO was confirmed with TEM images, besides its layered structure with lateral dimensions of some micrometers. GO- $\mathrm{NH}_{2}$ reserved this multilayered composition of GO due to the scrolling of nano-sheets as shown in its TEM image that retained its nanostructure and high surface area. This large surface area of GO was also confirmed from the SEM image that showed the agglomeration of GO in a 2-D multilayered composition with lateral sizes of some nanometers and a smooth surface. Shaded and bright areas can be formed on the surface of GO via the overlap of dissimilar layers. There was a similarity between the GO and GO-NH${ }_{2}$ SEM images with much folded and roughed GO- $\mathrm{NH}_{2}$ that retained the high surface area with a functionalization feature. The PAN nanoparticle growing over graphene sheets homogenously was confirmed from SEM and TEM images of HPAN-PRGO and PAN-PRGO. Hence, the amine-functionalized graphene oxide nanosheets grafted with PAN through polymerization. Figure $1 \mathrm{~g}$ shows the particle size distribution of HPAN-PRGO nanocomposite. From the TEM image and the histogram, the average particle size of HPAN-PRGO nanocomposite was $4.7 \mathrm{~nm}$. The average particle size was calculated by 174 measuring the diametersnanoparticles in TEM image by ImageJ software (ver 2, LOCI, Wisconsin, USA, 2014).

According to SEM, the HPAN and PAN nanoparticles had a narrow size distribution, mostly below $60 \mathrm{~nm}$. In addition, the SEM image's high magnification revealed spherical particles with sharp edges of PAN latex. The HPAN particles showed an increase in diameter when compared to PAN particles, due to the formation of amide $\left(\mathrm{CONH}_{2}\right)$ and carboxyl $(\mathrm{COOH})$ groups on the polymer chains by hydrolysis of cyano $(\mathrm{CN})$ groups, but no major change in overall morphology [28]. Although the bulk of the latexes are still made up of spherical crystals, evidence of neighboring latex conglutinating to one another at lateral points due to hydrolysis or crosslinking was discovered.

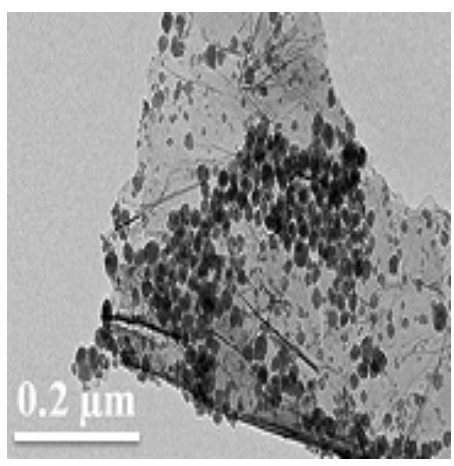

(a)

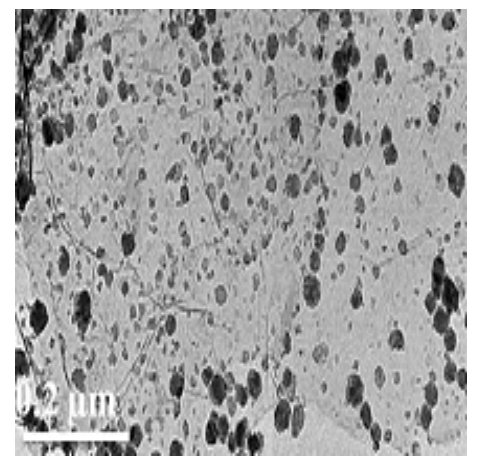

(b)

Figure 1. Cont. 


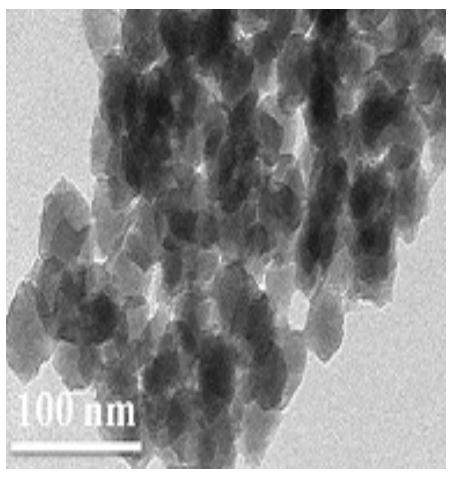

(c)

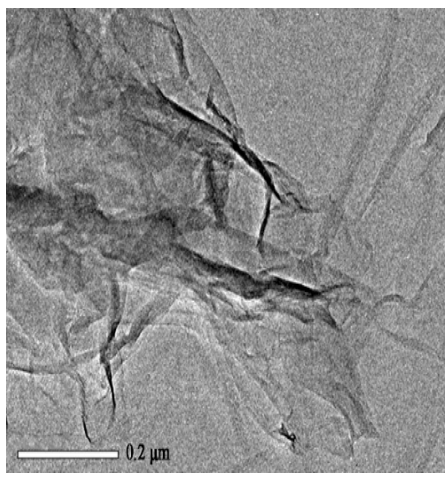

(e)

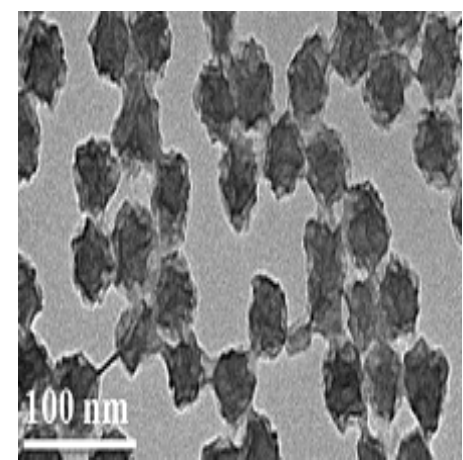

(d)

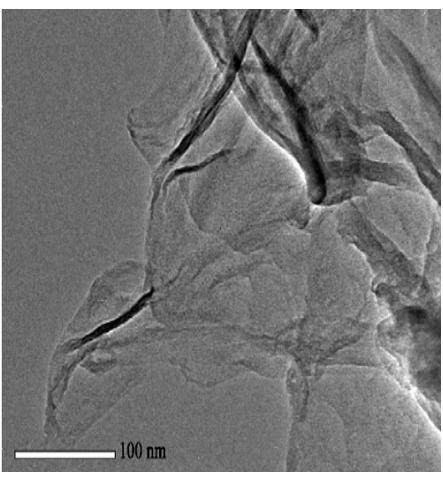

(f)

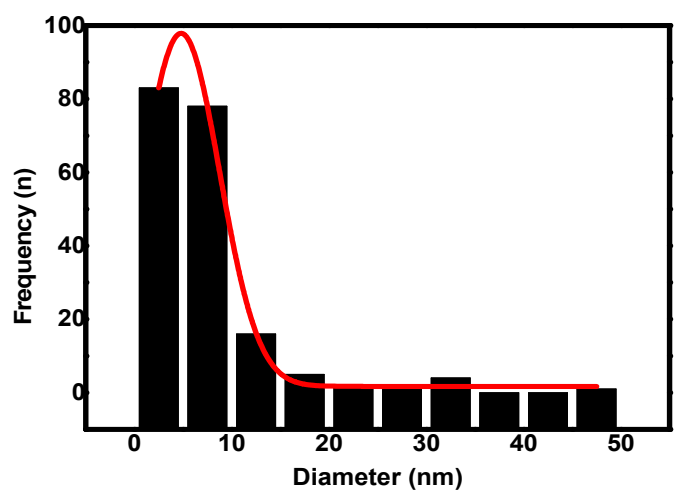

(g)

Figure 1. TEM image of (a) HPAN-PRGO; (b) PAN-PRGO; (c) HPAN; (d) PAN; (e) GO; (f) GO-NH $\mathrm{NH}_{2}$; and $(\mathrm{g})$ the particle size distribution of HPAN-PRGO nanocomposite.

The Raman spectra with two characteristic D and G bands of HPAN-PRGO, GO-NH $\mathrm{N}_{2}$, and GO are shown in Figure 3a. D and G bands are at 1357 and $1571 \mathrm{~cm}^{-1}$, respectively. The quality of graphitic constructions was determined using the $D$ band to $G$ band intensity ratio $\left(I_{D} / I_{G}\right)$, where this ratio for strongly ordered pyrolytic graphite reaches zero as an indicator of the defects and degree of disorder in the graphitic system. This ratio was calculated from three peaks and the value was the average of three values. This ratio in GO was found to be 0.94 which was a little more than the ratio in aminated GO that was equal to 1.13, which was attributed to the increased defects in GO structure due to the covalent bonding between $\mathrm{GO}$ sheets and ethylene diamine. The $\mathrm{GO}-\mathrm{NH}_{2} \mathrm{I}_{\mathrm{D}} / \mathrm{I}_{\mathrm{G}}$ ratio confirms the better quality of the prepared reduced GO, since this value should be between 1.12 and 1.42, as reported in the literature [29]. This ratio was also found to equal to 0.86 in HPAN-PRGO, which was lower than the ratio in GO, indicating the disordered 
structure due to the combination between free amino groups of GO sheets and nitrile groups of HPAN [24]. Synthesized materials including HPAN-PRGO, HPAN, GO-NH ${ }_{2}$, and GO were characterized using XRD as shown in Figure $3 \mathrm{~b}$. Due to the intermolecular repulsion of the nitrile dipoles, the HPAN spectrum shows a diffraction peak at $2 \theta=17.40$, which corresponds to the (100) crystallographic planes of PAN (due to PAN intermolecular spacing) [30]. The spectrum for HPAN-PRGO also indicates a poor reflection peak at $2 \theta=17.0$, which can be attributed to polyacrylonitrile's (100) crystal planes, implying that GO aids in the forming of PAN nanoparticles. The occurrence of a peak at $2 \theta=10.97$ in GO sheets produced by chemical oxidation of graphite is attributed to the functional oxygen-containing groups on the sheets [31]. The sharp peak of GO diminished after chemical functionalization with ethylene diamine, and a wide peak at $2 \theta=25.0$ existed, suggesting that the GO was partly reduced, possibly due to the restacking of the aminated GO nanosheets [32]. Based on Bragg's Law, the interlayer spacing for GO and GO- $\mathrm{NH}_{2}$ was 8.753 and $8.185 \AA$, respectively [33]. The decreased intensity of PAN peaks after implanting HPAN over aminated GO sheets indicated the reaction between the nitrile group of PAN and free amino groups of GO that caused the damage of bonds in the inner crystal area, and a reduction in the polar interaction between the molecular chains.

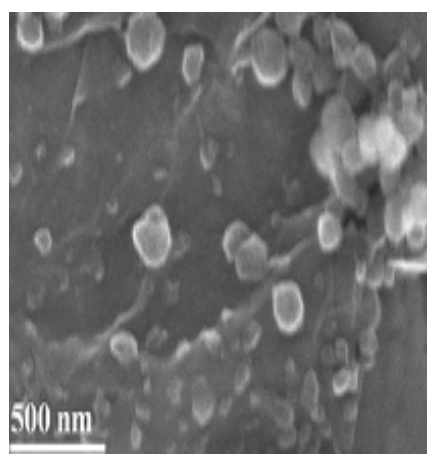

(a)

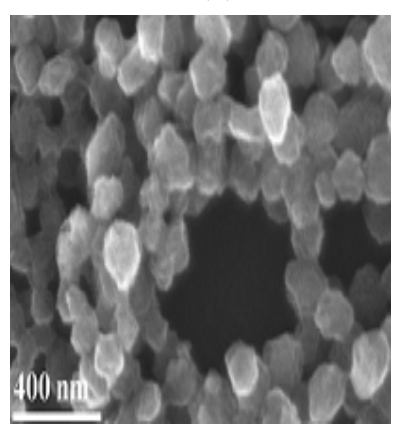

(c)

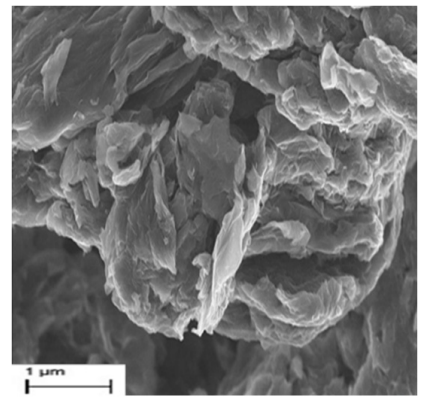

(e)

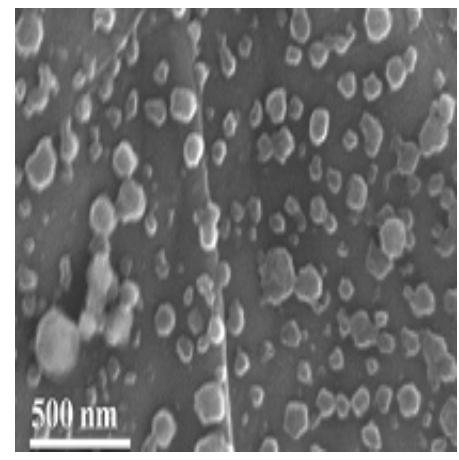

(b)

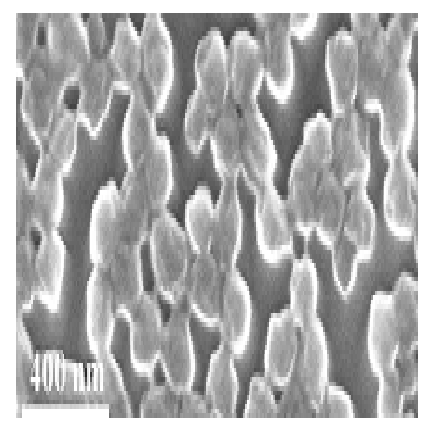

(d)

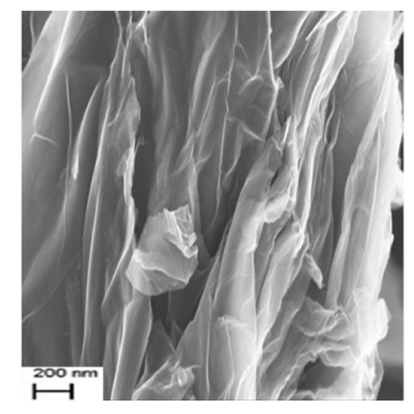

(f)

Figure 2. SEM image of (a) HPAN-PRGO; (b) PAN-PRGO; (c) HPAN; (d) PAN; (e) GO; and (f) GO-NH 2 . 


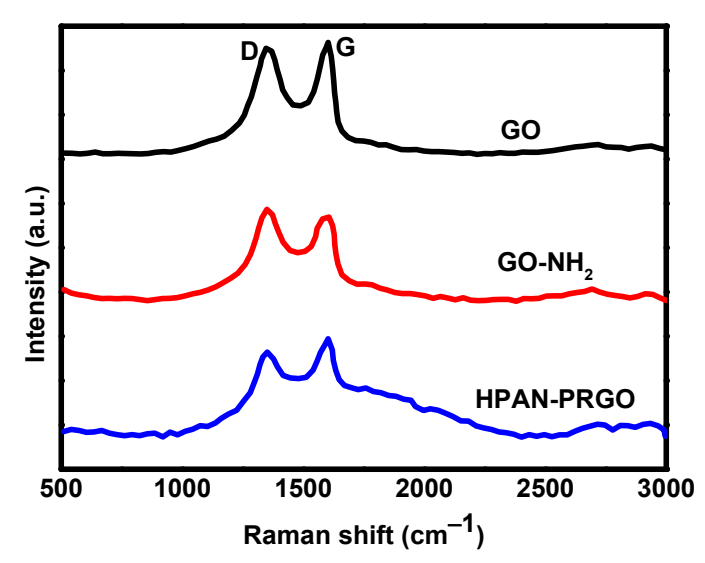

(a)

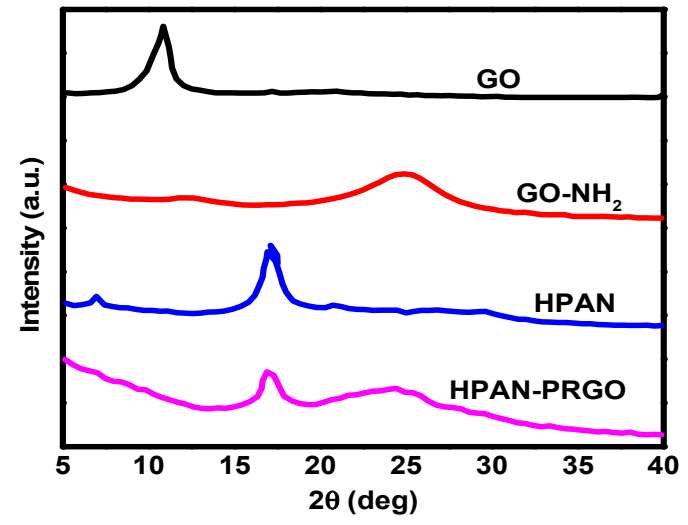

(b)

Figure 3. Raman spectra (a) and XRD (b) of synthesized materials.

FT-IR spectra of synthesized materials including HPAN-PRGO, HPAN, PAN-PRGO, PAN, GO-NH ${ }_{2}$, and GO are shown in Figure $4 a, b$ to approve their formation. The FT-IR of GO showed several peaks that corresponded to various functional oxygen groups, such as epoxy and alkoxy stretching, that appeared at 1158 and $1082 \mathrm{~cm}^{-1}$, respectively [34,35]; hydroxyl groups stretching vibrations appeared as a wide band at $3337 \mathrm{~cm}^{-1}$, and the carbonyl of the carboxylic group appeared at $1732 \mathrm{~cm}^{-1}$ [35]. The FT-IR spectra of aminofunctionalized GO showed two new peaks, for $\mathrm{N}-\mathrm{H}$ bending that appeared at $1652 \mathrm{~cm}^{-1}$, and $\mathrm{N}-\mathrm{H}$ stretching that was represented at $3273 \mathrm{~cm}^{-1}$ [36]. These bands show that the amine group and the amide linkage effectively functionalized graphene oxide with ethylene diamine. The characteristic peaks of PAN that appeared at 1460 and $2921 \mathrm{~cm}^{-1}$ represented $\mathrm{CH}_{2}$ bending and stretching vibrations, while the nitrile stretching vibration was represented by the peak at $2238 \mathrm{~cm}^{-1}$ [37]. Additionally, the nitrile group was confirmed by the peak at $1644 \mathrm{~cm}^{-1}$. The FT-IR spectra of PAN-PRGO showed a peak at $2921 \mathrm{~cm}^{-1}$, as in PAN, that corresponded to $\mathrm{CH}_{2}$ stretching vibration, and a peak corresponding to a nitrile group at $2239 \mathrm{~cm}^{-1}$. Additionally, the formation of $\mathrm{N}-\mathrm{C}=\mathrm{N}$ or $\mathrm{NH}-\mathrm{CO}$ due to the interaction between AN nitrile groups and amino-functionalized GO was confirmed by the appearance of a new peak corresponding to an amide group at $1574 \mathrm{~cm}^{-1}$, and the disappearance of or reduction in the amino-functionalized GO peaks at 1652 and $3273 \mathrm{~cm}^{-1}$. Additionally, $\mathrm{NH}-\mathrm{C}=\mathrm{N}-\mathrm{CH}_{2}$ formation was represented by the peaks at 1219 and $1460 \mathrm{~cm}^{-1}$. The FT-IR of PAN partially hydrolyzed using sodium hydroxide showed peaks at 1667 and $1574 \mathrm{~cm}^{-1}$, corresponding to amino and carbonyl stretching bands, and a reduced band at $2239 \mathrm{~cm}^{-1}$ after hydrolysis. The HPAN-PRGO FTIR spectra showed two new peaks at 1667 and $1574 \mathrm{~cm}^{-1}$ confirming the occurrence of hydrolysis. Additionally, the nitrile group band at $2239 \mathrm{~cm}^{-1}$ completely disappeared, while two overlapped peaks corresponding to COONa and $\mathrm{N}-\mathrm{H}$ were observed at 1574 and $1667 \mathrm{~cm}^{-1}$. The GO was confirmed to be partially reduced by the reduction in the epoxy group peak at $1082 \mathrm{~cm}^{-1}$. Thus, these results demonstrate that aminated GO was successfully produced, and that AN was simultaneously implanted and polymerized at the amino group of functionalized GO during the polymerization process, yielding covalently hybrid-prepared (HPAN-PRGO) nanocomposite. To determine the enhanced surface area of synthesized nanocomposite, the $\mathrm{N}_{2}$ adsorption-desorption isotherm of synthesized materials was performed and is shown in Figure 4c. The surface areas of HPAN, GO-NH ${ }_{2}$, and HPAN-PRGO were 27.0, 36.3 , and $58.0 \mathrm{~m}^{2} / \mathrm{g}$, respectively. The effect of modification on the surface area is clear from the isotherm curve that further affects the adsorption capacities toward the uptake of $\mathrm{Sm}^{3+}$ ions. 


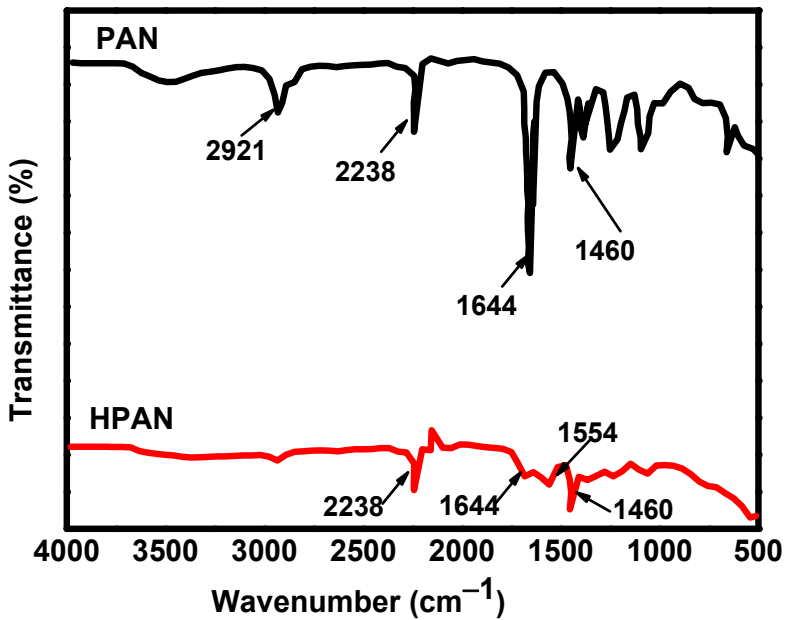

(a)

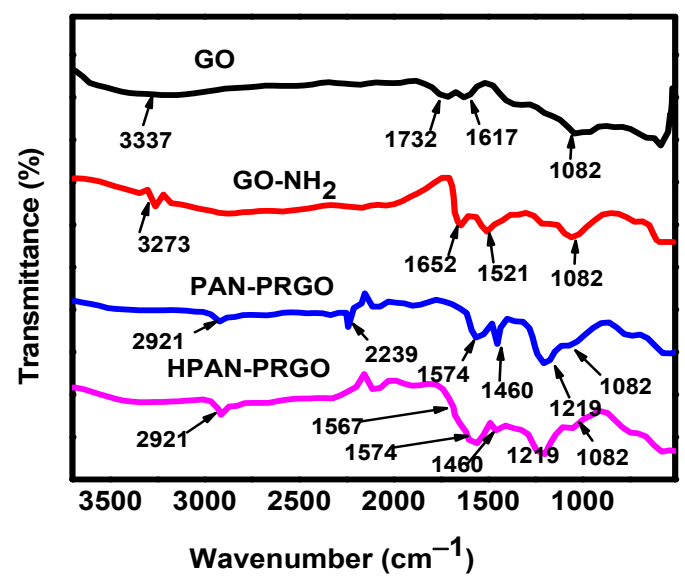

(b)

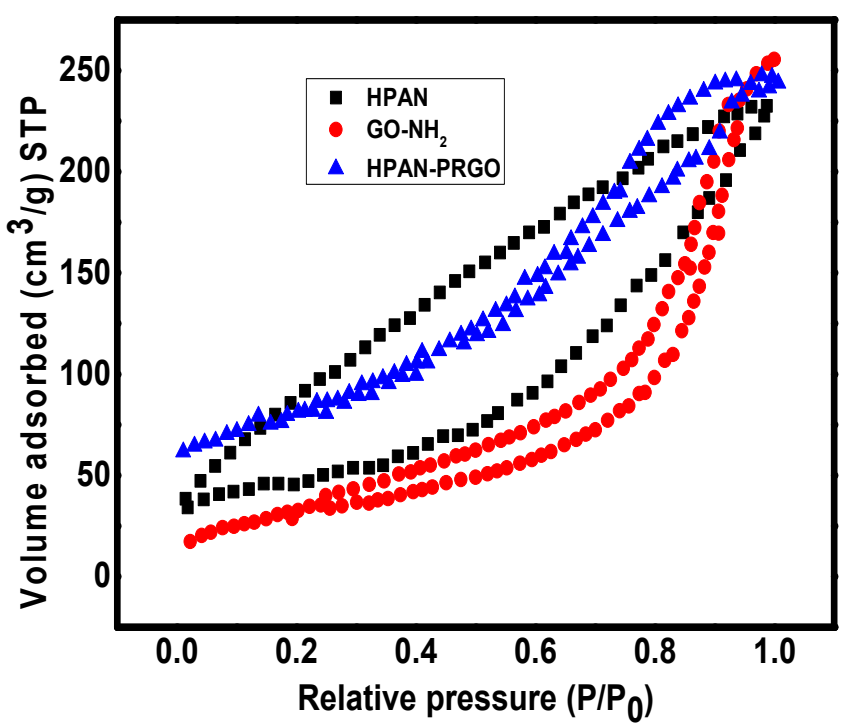

(c)

Figure 4. FT-IR of synthesized materials. (a) PAN and HPAN, (b) HPAN-PRGO, PAN-PRGO, GO-NH ${ }_{2}$, and GO, and (c) $\mathrm{N}_{2}$ adsorption-desorption isotherm.

\subsection{Initial Concentration Effect}

The effect of initial concentration on the adsorption of $\mathrm{Sm}^{3+}$ over synthesized materials was studied in the concentration range of $10-300 \mathrm{mg} / \mathrm{L}$, as shown in Figure $5 \mathrm{a}$. According to Figure $5 \mathrm{a}$, the adsorption capacity was increased as the initial concentration increased from 10 to $100 \mathrm{mg} / \mathrm{L}$. The maximum adsorption capacity for the removal of $\mathrm{Sm}^{3+}$ was reached at initial concentrations of 100, 100, and $50 \mathrm{mg} / \mathrm{L}$ in the case of HPAN-PRGO, GO$\mathrm{NH}_{2}$, and HPAN, respectively. After the equilibrium was reached there was no increase in the adsorption capacity with the increase in the initial concentration, meaning that there were no available sites for adsorption after reaching the equilibrium. The maximum adsorption capacities were 92.5, 74.0, and $22.7 \mathrm{mg} / \mathrm{g}$ for $\mathrm{Sm}^{3+}$ removal over HPAN-PRGO, GO-NH${ }_{2}$, and HPAN, respectively. 


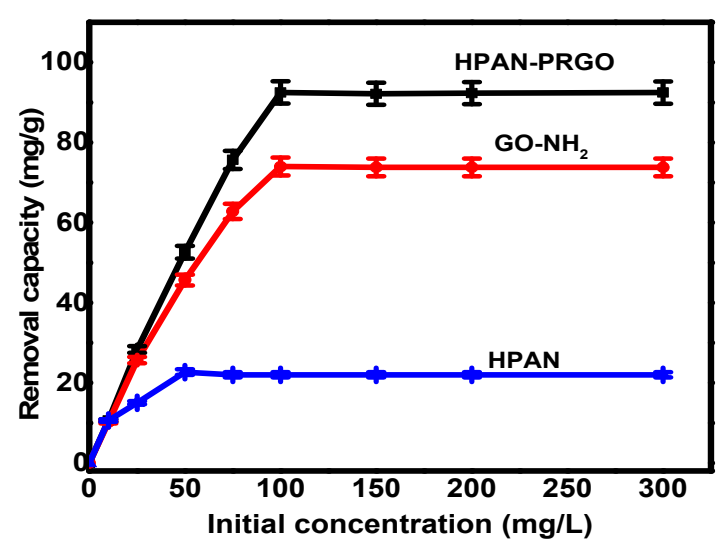

(a)

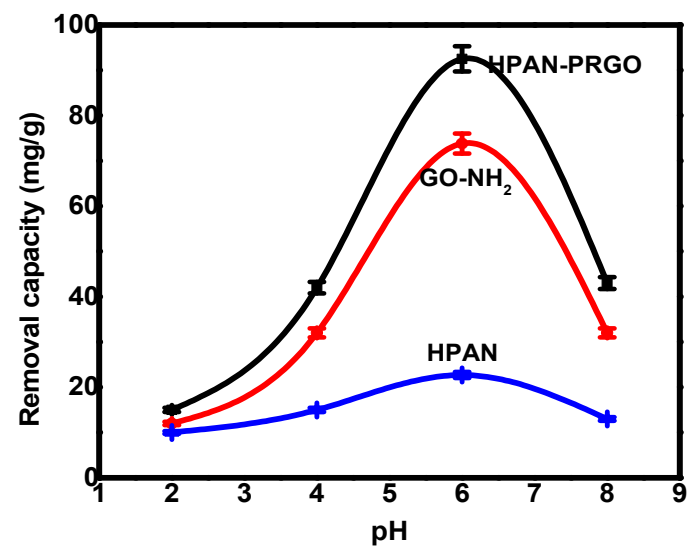

(b)

Figure 5. The effect of (a) the initial concentration and (b) solution $\mathrm{pH}$ on $\mathrm{Sm}^{3+}$ removal over $\mathrm{HPAN}-\mathrm{PRGO}, \mathrm{GO}-\mathrm{NH}{ }_{2}$, and HPAN.

\subsection{PH Effect}

The removal of $\mathrm{Sm}^{3+}$ ions over the synthesized HPAN-PRGO, GO-NH $\mathrm{N}_{2}$, and HPAN at different $\mathrm{pH}$ values was studied, as shown in Figure $5 \mathrm{~b}$. The studied $\mathrm{pH}$ range was 2.0 to 8.0 , adjusted using $0.1 \mathrm{~N}$ of $\mathrm{HCl}$ and $\mathrm{NaOH}$. For all studied adsorbents, the maximum adsorption capacities were reached at $\mathrm{pH}$ equal to 6.0, and found to be 92.5, 74.0, and $22.7 \mathrm{mg} / \mathrm{g}$ for HPAN-PRGO, GO-NH $\mathrm{N}_{2}$, and HPAN, respectively. According to Figure 5b, the relationship between sorption and solution $\mathrm{pH}$ has an extreme principle. The adsorption of $\mathrm{Sm}^{3+}$ ions increased with $\mathrm{pH}$ increasing, peaked around $\mathrm{pH} 6.0$, and then started to drop again. The low adsorption capacities of different adsorbents at $\mathrm{pH}<6$ was attributed to the protonated state of adsorbent functional groups $\left(\mathrm{O}=\mathrm{C}-\mathrm{NH}^{+}, \mathrm{NH}_{3}{ }^{+}\right.$, and $\left.\mathrm{COOH}^{+}{ }_{2}\right)$ causing an increase in the electrostatic repulsion with the positive samarium ions, while at $\mathrm{pH}>6$ the adsorption capacities decreased due to the precipitation of $\mathrm{Sm}^{3+}$ ions as hydroxides, which made their capture by the adsorbent decrease and may have been due to competitive adsorption from hydroxyl ions caused by hydrogen bonding formation, resulting in a reduction in the amount of possible adsorption sites. Further experiments were performed at $\mathrm{pH}$ equal to 6.0 as the results in this section indicated that the optimum $\mathrm{pH}$ value was 6.0.

\subsection{Contact Time Effect}

The contact time effect on $\mathrm{Sm}^{3+}$ adsorption over HPAN, GO-NH 2 , and HPAN-PRGO was studied over a time range of 10 to $60 \mathrm{~min}$ and the results are shown in Figure $6 \mathrm{a}$. According to Figure $6 \mathrm{a}$, most $\mathrm{Sm}^{3+}$ ions interacted rapidly with the synthesized materials HPAN, GO- $\mathrm{NH}_{2}$, and HPAN-PRGO during the first 10 min of the removal process. This rapid stage occurred due to the existence of empty adsorption sites with a large number on the surface of the adsorbent that caused the rapid capture of ions within a short period. After that, the equilibrium was achieved within $15 \mathrm{~min}$, which caused this time to be chosen as the optimum contact time. The repulsive forces between the adsorbed ions were augmented when the quantity of $\mathrm{Sm}^{3+}$ adsorbed onto the adsorbent increased, and adsorption tolerance for free metal ions was exacerbated accordingly. Hence, after reaching the equilibrium, there was no further increase in the adsorption capacities due to repulsion forces, as well as the occupancy of adsorption sites with ions, and there were no free sites to capture additional ions, so time became without effect on the adsorption process. 


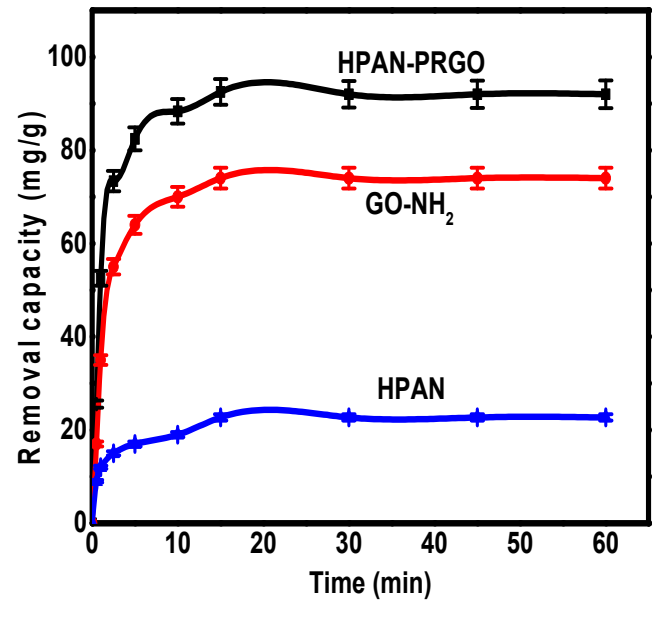

(a)

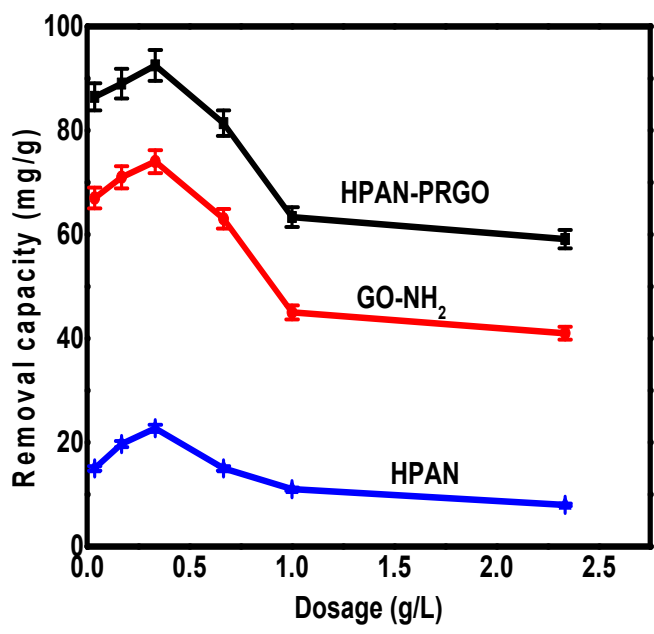

(b)

Figure 6. The effect of (a) contact time and (b) the dose on $\mathrm{Sm}^{3+}$ removal over HPAN-PRGO, GO-NH ${ }_{2}$, and HPAN.

\subsection{Dose Effect}

The dose effect on the adsorption of $\mathrm{Sm}^{3+}$ ions over HPAN, GO-NH${ }_{2}$, and HPANPRGO was studied over a range of 0.1 to $2.5 \mathrm{~g} / \mathrm{L}$ and the results are shown in Figure $6 \mathrm{~b}$. This study aimed to investigate the effect of adsorbent weight on $\mathrm{Sm}^{3+}$ removal using synthesized nanocomposites. According to Figure $6 \mathrm{~b}$, the adsorption capacities reached their maximum at $0.3 \mathrm{~g} / \mathrm{L}$, which was equal to 23,74 , and $93 \mathrm{mg} / \mathrm{g}$ for HPAN, GO-NH${ }_{2}$, and HPAN-PRGO, respectively. However, at higher doses, the adsorption capacities decreased. The range from 0.1 to $0.3 \mathrm{~g} / \mathrm{L}$ showed an increase in the adsorption capacities toward $\mathrm{Sm}^{3+}$ ions, with approximately $15 \%$ of that attributed to the fixed volume of solution in this case that lead to an increase in the chance of adsorbent interaction with pollutant ions. At definite dosage, a redistribution of the metal ions in a higher volume of adsorbent occurs with any further increase in the adsorbent dosage, and the contact efficacy stops limiting the adsorption. Accordingly, there was a drop in the adsorption activity per unit mass of adsorbent at this dosage.

\subsection{Adsorption Isotherm}

The maximum adsorption capacity of captured ions can be possibly investigated by plotting the adsorption isotherm. Different isotherms can describe the interaction between pollutant ions and active sites of adsorbent and describe also the isotherm behavior, such as the length of the linear section, the existence of a bending section, and degree of curvature, etc. The studied isotherms hit plateaus in a given concentration range, as shown in Figure 7. Langmuir and Freundlich isotherm models were used to fit the equilibrium data, as shown in Figure 7a,b, respectively, and the obtained parameters for both isotherms are introduced in Table 1.

Table 1. Freundlich and Langmuir adsorption isotherms' different parameters for $\mathrm{Sm}^{3+}$ adsorption over synthesized nanomaterials.

\begin{tabular}{|c|c|c|c|c|c|c|}
\hline \multirow[t]{2}{*}{ Adsorbent } & \multicolumn{3}{|c|}{ Freundlich } & \multicolumn{3}{|c|}{ Langmuir } \\
\hline & $\mathbf{K}_{\mathrm{F}}$ & $\mathbf{N}$ & $\mathbf{R}^{2}$ & $\mathrm{q}_{\mathrm{m}}$ & $\mathbf{R}_{\mathrm{L}}$ & $\mathbf{R}^{2}$ \\
\hline $\begin{array}{l}\text { HPAN- } \\
\text { PRGO }\end{array}$ & 84.523 & 4.486 & 0.846 & 357 & 0.015 & 0.998 \\
\hline GO-NH${ }_{2}$ & 38.553 & 3.7 & 0.937 & 218 & 0.035 & 0.994 \\
\hline HPAN & 21.76 & 3.954 & 0.947 & 82 & 0.032 & 0.996 \\
\hline
\end{tabular}




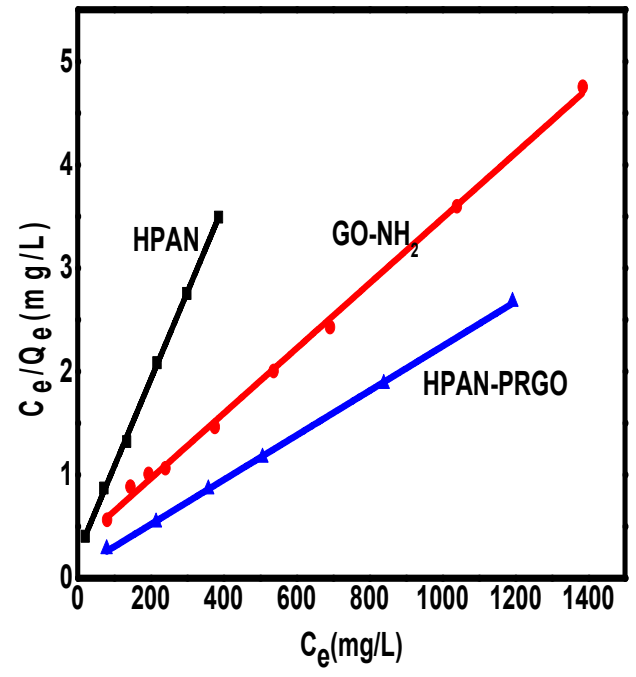

(a)

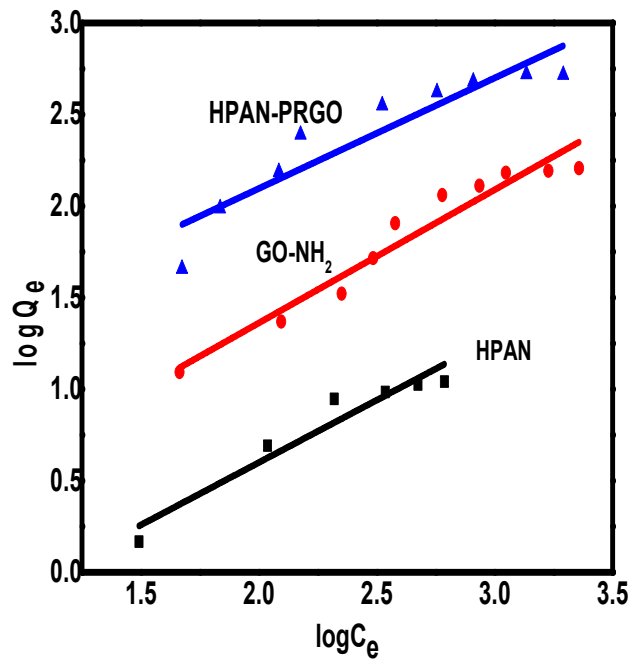

(b)

Figure 7. (a) Langmuir linear fitted curve and (b) Freundlich linear fitted curve for the removal of $\mathrm{Sm}^{3+}$ ions over HPANPRGO, GO-NH${ }_{2}$, and HPAN.

For HPAN-PRGO, GO-NH${ }_{2}$, and HPAN materials as adsorbents for the capture of $\mathrm{Sm}^{3+}$ ions, the experimental data fit lower to the Freundlich model isotherm than to the Langmuir model isotherm, based on the $\mathrm{R}_{\mathrm{L}}$ (dimensionless constant) values that fell in the favorable range (0-1) and based on $\mathrm{R}^{2}$ (correlation coefficient) values. These values indicated that $\mathrm{Sm}^{3+}$ ion capture using HPAN-PRGO, GO-NH${ }_{2}$, and HPAN nanomaterials were a better fit to the Langmuir isotherm model than the Freundlich model. The monolayer of adsorbed ions is designed on the adsorbent surface according to Langmuir's theory and the enthalpy of adsorption sites, and the energy is identical while a heterogeneous adsorption is described according to Freundlich's theory [38].

According to this, the $\mathrm{Sm}^{3+}$ ions are adsorbed over HPAN-PRGO, GO-NH $\mathrm{N}_{2}$, and HPAN nanomaterials in a monolayer by active adsorption sites that are energetically identical. Subsequently, it is fair to say that the synthesized substances have homogeneous composition, with the same adsorption core geometry, resulting in identical adsorption forces for ion extraction from aqueous solutions. According to the Langmuir isotherm, the maximum adsorption capacities are 357,218 , and $82 \mathrm{mg} / \mathrm{g}$ for the $\mathrm{Sm}^{3+}$ ions' adsorption over HPAN-PRGO, GO-NH , and HPAN, respectively. These results of the isotherm indicate the capture of a high quantity of $\mathrm{Sm}^{3+}$ ions that is attributed to the existence of carboxylate and amine groups with a large number over the nanocomposite surface.

\subsection{Reusability Study}

The ability to reuse any adsorbent is a key factor determining the overall cost of water treatment processes $[39,40]$. The reusability study of the adsorbent has been carried out by repeating the pollutant ion adsorption-desorption cycle many times by the same adsorbent [41-43]. The desorption here of $\mathrm{Sm}^{3+}$ ions was achieved using $2 \mathrm{M} \mathrm{HCl}$ and buffer solution. Then, the desorbed HPAN-PRGO nanocomposite was washed with sodium hydroxide to retain the -ve charge of the adsorbent carboxylic groups. After that, the adsorbent was washed several times with deionized $\mathrm{H}_{2} \mathrm{O}$ and dried to be used in the next cycle. The adsorption-desorption process for $\mathrm{Sm}^{3+}$ ion removal using HPAN-PRGO nanocomposite was performed up to six successive cycles. The reversibility of the adsorption process and excellent regeneration properties of the HPAN-PRGO nanocomposite for $\mathrm{Sm}^{3+}$ removal was indicated from the loss in the removal efficiency after six cycles, which was found to be only 5\% compared to the first cycle, as shown in Figure 8 . After the last cycle, the removal efficiency was maintained above $90 \%$. Based on these findings, it can be 
suggested that the HPAN-PRGO adsorbent can be used continuously to remove $\mathrm{Sm}^{3+}$ ions from water with low cost and high efficiency.

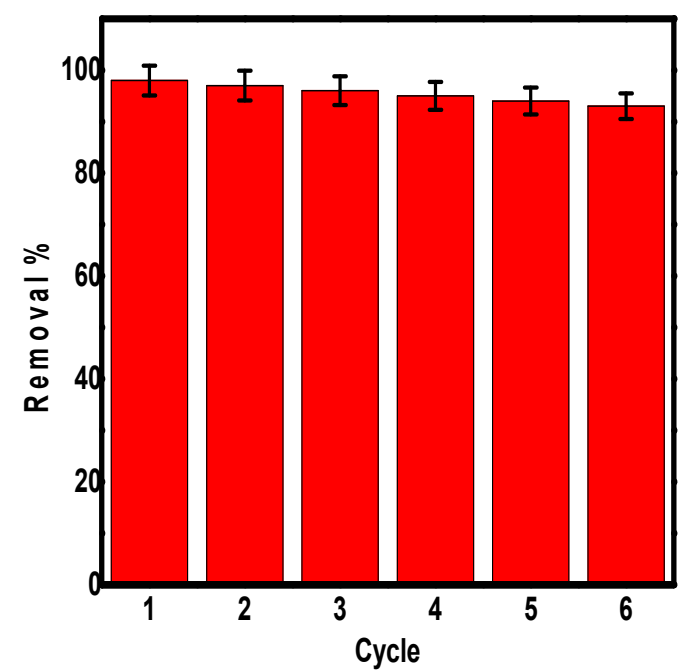

Figure 8. Reusability study of HPAN-PRGO nanocomposite for the removal of $\mathrm{Sm}^{3+}$ ions up to six successive cycles.

\subsection{Comparative Study of Samarium Ions Adsorption}

To highlight the effectiveness of the synthesized material as an $\mathrm{Sm}^{3+}$ adsorbent, the maximum adsorption capacity obtained here for $\mathrm{Sm}^{3+}$ ions was compared with previously reported results. The previous studies for $\mathrm{Sm}^{3+}$ adsorption are summarized in Table 2 . According to previously reported results, HPAN-PRGO nanocomposite revealed excellent adsorption capacity for $\mathrm{Sm}^{3+}$ ion removal compared to reported adsorbents. Therefore, synthesized HPAN-PRGO nanocomposite may be effectively used for the capture of $\mathrm{Sm}^{3+}$ ions from aqueous solution. An important study that must be considered in the future is to determine the thermodynamic parameters $(\Delta \mathrm{G}, \Delta \mathrm{H}$, and $\Delta \mathrm{S})$ [44-48] of the adsorption process to get a complete picture regarding the applicability of the HPAN-PRGO nanocomposite in large-scale water treatment.

Table 2. Comparison between the removal of $\mathrm{Sm}^{3+}$ ions over HPAN-PRGO nanocomposite and previous studies.

\begin{tabular}{|c|c|c|}
\hline Adsorbent & Adsorption Capacity (mg/g) & Ref. \\
\hline HPAN-PRGO & 357.0 & This study \\
\hline Oxidized MWCNTs & 89.3 & [49] \\
\hline $\mathrm{Fe}_{2} \mathrm{O}_{3} / \mathrm{SiO}_{2} / \mathrm{R}_{1} \mathrm{R}_{2} \mathrm{PO}_{3} \mathrm{Na}$ & 180.0 & [50] \\
\hline Mesoporous $\mathrm{Fe}_{3} \mathrm{O}_{4} \mathrm{mSiO}_{2}$-DODGA nanoparticles & 28.60 & [51] \\
\hline ZIF-8 NPs & 281.10 & [52] \\
\hline $\mathrm{SiO}_{2} / \mathrm{PVI} / \mathrm{H}_{2} \mathrm{PO}_{4}^{-} \mathrm{NPs}$ & 160.0 & [53] \\
\hline Sargassum Sp. & 51.10 & [54] \\
\hline PAN SDS & 97.70 & [55] \\
\hline samarium (III) ion-imprinted polymer (IIP) particles & 12.25 & [56] \\
\hline Heulandite & 8.53 & [57] \\
\hline
\end{tabular}

However, is very important to point out that the material cost is an important factor prohibiting the widespread use of composites at a large scale. In some cases, recent advances in composites are driving composites to be more competitive and cost effective. Concerning the material tested in the present study, more investigations are needed to 
evaluate the process efficiency using real wastewater at a large scale. Additionally, the competitive applicability of this innovative adsorbent should be evaluated, taking into consideration various parameters related to the material proprieties (degradation life cycle, regeneration, etc.) and to the waste generated by the process, including the loaded pollutant's disposal and chemicals used for the adsorption/desorption process. Moreover, cost comparison between this innovative adsorbent and other materials should be conducted.

\section{Conclusions}

In this study, HPAN-PRGO nanocomposite as a novel adsorbent was synthesized successfully and applied for the removal of samarium ions from water. The synthesized HPAN-PRGO nanocomposite was characterized using various techniques (SEM, TEM, FT-IR, and XRD). The experimental results for $\mathrm{Sm}^{3+}$ ion removal over HPAN-PRGO nanocomposite were found to fit well with the Langmuir model, with a maximum adsorption capacity equal to $357 \mathrm{mg} / \mathrm{g}$. This indicated that the ions were adsorbed over the surface of the nanocomposite as a monolayer via energetically identical adsorption sites. Interestingly, the nanocomposite reuse was investigated up to six successive cycles with no significant loss in the $\mathrm{Sm}^{3+}$ removal efficiency. Finally, we can conclude that HPAN-PRGO nanocomposite can be considered as a promising material for water treatment that could be studied for the removal of additional metals and dyes.

Author Contributions: Conceptualization, A.A., N.S.A., K.M.K., F.M.A., M.A.T., and F.B.R.; methodology, A.A., N.S.A., K.M.K., F.M.A., M.A.T., and F.B.R.; formal analysis; data curation, A.A., N.S.A., K.M.K., F.M.A., M.A.T., and F.B.R.; writing-original draft preparation, A.A., N.S.A., K.M.K., F.M.A., and M.A.T.; writing-review and editing, A.A., N.S.A., K.M.K., F.M.A., M.A.T., and F.B.R.; visualization; F.B.R. All authors have read and agreed to the published version of the manuscript.

Funding: This research was funded by the Deanship of Scientific Research at King Khalid University.

Institutional Review Board Statement: Not applicable.

Informed Consent Statement: Not applicable.

Data Availability Statement: Not applicable.

Acknowledgments: The authors extend their appreciation to the Deanship of Scientific Research at King Khalid University for funding this work through the research groups program under grant number R.G.P.2/157/42. Additionally, this research was funded by the Deanship of Scientific Research at Princess Nourah bint Abdulrahman University through the Fast-track Research Funding Program.

Conflicts of Interest: The authors declare no conflict of interest.

\section{References}

1. Siddeeg, S.M.; Tahoon, M.A.; Alsaiari, N.S.; Shabbir, M.; Rebah, F.B. Application of functionalized nanomaterials as effective adsorbents for the removal of heavy metals from wastewater: A review. Curr. Anal. Chem. 2021, 17, 4-22. [CrossRef]

2. Siddeeg, S.M.; Tahoon, M.A.; Rebah, F.B. Agro-industrial waste materials and wastewater as growth media for microbial bioflocculants production: A review. Mater. Res. Express 2019, 7, 012001. [CrossRef]

3. Tahoon, M.A.; Siddeeg, S.M.; Salem Alsaiari, N.; Mnif, W.; Ben Rebah, F. Effective heavy metals removal from water using nanomaterials: A review. Processes 2020, 8, 645. [CrossRef]

4. Amari, A.; Elboughdiri, N.; Ghernaout, D.; Lajimi, R.H.; Alshahrani, A.M.; Tahoon, M.A.; Rebah, F.B. Multifunctional crosslinked chitosan/nitrogen-doped graphene quantum dot for wastewater treatment. Ain Shams Eng. J. 2021. [CrossRef]

5. Afonso, E.L.; Carvalho, L.; Fateixa, S.; Amorim, C.O.; Amaral, V.S.; Vale, C.; Pereira, E.; Silva, C.M.; Trindade, T.; Lopes, C.B. Can contaminated waters or wastewater be alternative sources for technology-critical elements? The case of removal and recovery of lanthanides. J. Hazard. Mater. 2019, 380, 120845. [CrossRef] [PubMed]

6. Teh, C.M.; Mohamed, A.R. Roles of titanium dioxide and ion-doped titanium dioxide on photocatalytic degradation of organic pollutants (phenolic compounds and dyes) in aqueous solutions: A review. J. Alloy. Compd. 2011, 509, 1648-1660. [CrossRef]

7. Romero-Freire, A.; Joonas, E.; Muna, M.; Cossu-Leguille, C.; Vignati, D.; Giamberini, L. Assessment of the toxic effects of mixtures of three lanthanides (Ce, Gd, Lu) to aquatic biota. Sci. Total Environ. 2019, 661, 276-284. [CrossRef] [PubMed]

8. Haley, T.; Raymond, K.; Komesu, N.; Upham, H. Toxicological and pharmacological effects of gadolinium and samarium chlorides. Br. J. Pharmacol. Chemother. 1961, 17, 526-532. [CrossRef] [PubMed] 
9. Yesiller, S.U.; Eroğlu, A.; Shahwan, T. Removal of aqueous rare earth elements (REEs) using nano-iron based materials. J. Ind. Eng. Chem. 2013, 19, 898-907. [CrossRef]

10. Ali, O.; Osman, H.; Sayed, S.; Shalabi, M. The removal of some rare earth elements from their aqueous solutions on by-pass cement dust (BCD). J. Hazard. Mater. 2011, 195, 62-67. [CrossRef]

11. Rahman, M.L.; Biswas, T.K.; Sarkar, S.M.; Yusoff, M.M.; Sarjadi, M.S.; Arshad, S.E.; Musta, B. Adsorption of rare earth metals from water using a kenaf cellulose-based poly (hydroxamic acid) ligand. J. Mol. Liq. 2017, 243, 616-623. [CrossRef]

12. Vijayaraghavan, K.; Rangabhashiyam, S.; Ashokkumar, T.; Arockiaraj, J. Assessment of samarium biosorption from aqueous solution by brown macroalga Turbinaria conoides. J. Taiwan Inst. Chem. Eng. 2017, 74, 113-120. [CrossRef]

13. Callura, J.C.; Shi, Q.; Dzombak, D.A.; Karamalidis, A.K. Selective recovery of rare earth elements with ligand-functionalized polymers in fixed-bed adsorption columns. Sep. Purif. Technol. 2021, 265, 118472. [CrossRef]

14. Talan, D.; Huang, Q. Separation of radionuclides from a rare earth-containing solution by zeolite adsorption. Minerals 2021, 11, 20. [CrossRef]

15. Botelho Junior, A.B.; Pinheiro, É.F.; Espinosa, D.C.R.; Tenório, J.A.S.; Baltazar, M.D.P.G. Adsorption of lanthanum and cerium on chelating ion exchange resins: Kinetic and thermodynamic studies. Sep. Sci. Technol. 2021, 1-10. [CrossRef]

16. Missana, T.; Alonso, U.; García-Gutiérrez, M. Evaluation of component additive modelling approach for europium adsorption on 2:1 clays: Experimental, thermodynamic databases, and models. Chemosphere 2021, 272, 129877. [CrossRef] [PubMed]

17. Huang, C.; Cai, B.; Zhang, L.; Zhang, C.; Pan, H. Preparation of iron-based metal-organic framework@ cellulose aerogel by in situ growth method and its application to dye adsorption. J. Solid State Chem. 2021, 297, 122030. [CrossRef]

18. Amari, A.; Alzahrani, F.M.; Mohammedsaleh Katubi, K.; Alsaiari, N.S.; Tahoon, M.A.; Rebah, F.B. Clay-polymer nanocomposites: Preparations and utilization for pollutants removal. Materials 2021, 14, 1365. [CrossRef]

19. Kampalanonwat, P.; Supaphol, P. Preparation and adsorption behavior of aminated electrospun polyacrylonitrile nanofiber mats for heavy metal ion removal. ACS Appl. Mater. Interfaces 2010, 2, 3619-3627. [CrossRef]

20. Siddeeg, S.M.; Amari, A.; Tahoon, M.A.; Alsaiari, N.S.; Rebah, F.B. Removal of meloxicam, piroxicam and Cd+ 2 by $\mathrm{Fe} 3 \mathrm{O} 4 / \mathrm{SiO} 2 /$ glycidyl methacrylate-S-SH nanocomposite loaded with laccase. Alex. Eng. J. 2020, 59, 905-914. [CrossRef]

21. Mahmoud, M.E.; Nabil, G.M.; Elweshahy, S.M. Novel NTiO2-chitosan@ NZrO2-chitosan nanocomposite for effective adsorptive uptake of trivalent gadolinium and samarium ions from water. Powder Technol. 2021, 378, 246-254. [CrossRef]

22. Alsaiari, N.S.; Katubi, K.M.M.; Alzahrani, F.M.; Siddeeg, S.M.; Tahoon, M.A. The application of nanomaterials for the electrochemical detection of antibiotics: A review. Micromachines 2021, 12, 308. [CrossRef] [PubMed]

23. Amari, A.; Alalwan, B.; Siddeeg, S.M.; Tahoon, M.A.; Alsaiari, N.S.; Rebah, F.B. Biomolecules behavior on a surface of boron doped/un-doped graphene nanosheets. Int. J. Electrochem. Sci. 2020, 15, 11427-11436. [CrossRef]

24. Chandra, V.; Kim, K.S. Highly selective adsorption of $\mathrm{Hg} 2+$ by a polypyrrole-reduced graphene oxide composite. Chem. Commun. 2011, 47, 3942-3944. [CrossRef] [PubMed]

25. Pekel, N.; Şahiner, N.; Güven, O. Use of amidoximated acrylonitrile/N-vinyl 2-pyrrolidone interpenetrating polymer networks for uranyl ion adsorption from aqueous systems. J. Appl. Polym. Sci. 2001, 81, 2324-2329. [CrossRef]

26. Marcano, D.C.; Kosynkin, D.V.; Berlin, J.M.; Sinitskii, A.; Sun, Z.; Slesarev, A.; Alemany, L.B.; Lu, W.; Tour, J.M. Improved synthesis of graphene oxide. ACS Nano 2010, 4, 4806-4814. [CrossRef] [PubMed]

27. Zhang, Y.; Zhuang, X.; Gu, W.; Zhao, J. Synthesis of polyacrylonitrile nanoparticles at high monomer concentrations by AIBNinitiated semi-continuous emulsion polymerization method. Eur. Polym. J. 2015, 67, 57-65. [CrossRef]

28. Deng, S.; Wang, P.; Zhang, G.; Dou, Y. Polyacrylonitrile-based fiber modified with thiosemicarbazide by microwave irradiation and its adsorption behavior for Cd (II) and Pb (II). J. Hazard. Mater. 2016, 307, 64-72. [CrossRef] [PubMed]

29. Singh, S.K.; Singh, M.K.; Kulkarni, P.P.; Sonkar, V.K.; Grácio, J.J.; Dash, D. Amine-modified graphene: Thrombo-protective safer alternative to graphene oxide for biomedical applications. ACS Nano 2012, 6, 2731-2740. [CrossRef] [PubMed]

30. Li, G.; Xiao, J.; Zhang, W. Efficient and reusable amine-functionalized polyacrylonitrile fiber catalysts for Knoevenagel condensation in water. Green Chem. 2012, 14, 2234-2242. [CrossRef]

31. Katubi, K.M.M.; Alsaiari, N.S.; Alzahrani, F.M.; Siddeeg, S.M.; Tahoon, M.A. Synthesis of manganese ferrite/graphene oxide magnetic nanocomposite for pollutants removal from water. Processes 2021, 9, 589. [CrossRef]

32. Cai, X.; Lin, M.; Tan, S.; Mai, W.; Zhang, Y.; Liang, Z.; Lin, Z.; Zhang, X. The use of polyethyleneimine-modified reduced graphene oxide as a substrate for silver nanoparticles to produce a material with lower cytotoxicity and long-term antibacterial activity. Carbon 2012, 50, 3407-3415. [CrossRef]

33. Bragg, W.H.; Bragg, W.L. The reflection of X-rays by crystals. Proc. R. Soc. Lond. Ser. A Contain. Pap. Math. Phys. Character 1913, 88, 428-438. [CrossRef]

34. Ossonon, B.D.; Bélanger, D. Synthesis and characterization of sulfophenyl-functionalized reduced graphene oxide sheets. RSC Adv. 2017, 7, 27224-27234. [CrossRef]

35. Shahriary, L.; Athawale, A.A. Graphene oxide synthesized by using modified hummers approach. Int. J. Renew. Energy Environ. Eng 2014, 2, 58-63.

36. Jebaranjitham, J.N.; Mageshwari, C.; Saravanan, R.; Mu, N. Fabrication of amine functionalized graphene oxide-AgNPs nanocomposite with improved dispersibility for reduction of 4-nitrophenol. Compos. Part B Eng. 2019, 171, 302-309. [CrossRef]

37. Ji, L.; Zhang, X. Ultrafine polyacrylonitrile/silica composite fibers via electrospinning. Mater. Lett. 2008, 62, 2161-2164. [CrossRef] 
38. Alsaiari, N.S.; Amari, A.; Katubi, K.M.; Alzahrani, F.M.; Rebah, F.B.; Tahoon, M.A. Innovative magnetite based polymeric nanocomposite for simultaneous removal of methyl orange and hexavalent chromium from water. Processes $2021,9,576$. [CrossRef]

39. Siddeeg, S.M.; Tahoon, M.A.; Mnif, W.; Ben Rebah, F. Iron oxide/chitosan magnetic nanocomposite immobilized manganese peroxidase for decolorization of textile wastewater. Processes 2020, 8, 5. [CrossRef]

40. Siddeeg, S.M.; Tahoon, M.A.; Ben Rebah, F. Simultaneous removal of calconcarboxylic acid, NH4+ and PO43- from pharmaceutical effluent using iron oxide-biochar nanocomposite loaded with Pseudomonas putida. Processes 2019, 7, 800. [CrossRef]

41. Cesar Filho, M.; Bueno, P.V.; Matsushita, A.F.; Rubira, A.F.; Muniz, E.C.; Durães, L.; Murtinho, D.M.; Valente, A.J. Synthesis, characterization and sorption studies of aromatic compounds by hydrogels of chitosan blended with $\beta$-cyclodextrin-and PVAfunctionalized pectin. RSC Adv. 2018, 8, 14609-14622. [CrossRef]

42. Utzeri, G.; Verissimo, L.; Murtinho, D.; Pais, A.A.; Perrin, F.X.; Ziarelli, F.; Iordache, T.-V.; Sarbu, A.; Valente, A.J. Poly ( $\beta$ cyclodextrin)-activated carbon gel composites for removal of pesticides from water. Molecules 2021, 26, 1426. [CrossRef] [PubMed]

43. Bueno, P.V.; Matsushita, A.F.; Vilsinski, B.H.; Rubira, A.F.; Muniz, E.C.; Murtinho, D.; Valente, A.J. Uncommon sorption mechanism of aromatic compounds onto poly (vinyl alcohol)/chitosan/maleic anhydride- $\beta$-cyclodextrin hydrogels. Polymers 2020, $12,877$.

44. Ben Rebah, F.; Siddeeg, S.M.; Tahoon, M.A. Thermodynamic parameters and solvation behavior of 1-ethyle-3-methylimidazolium tetrafluoroborate and 1-butyl-3-methylimidazolium tetrafluoroborate in N, N-dimethylformamide and acetonitrile at different temperature. Egypt. J. Chem. 2019, 62, 393-404.

45. Tahoon, M.; Gomaa, E.; Suleiman, M. Aqueous micro-hydration of $\mathrm{Na}+\left(\mathrm{H}_{2} \mathrm{O}\right) \mathrm{n}=1-7$ clusters: DFT study. Open Chem. 2019, 17, 260-269.

46. Gomaa, E.A.; Tahoon, M.A.; Shokr, A. Ionic association and solvation study of $\mathrm{CoSO}_{4}$ in aqueous-organic solvents at different temperatures. Chem. Data Collect. 2016, 3, 58-67. [CrossRef]

47. Gomaa, E.A.; Tahoon, M.A.; Negm, A. Aqueous micro-solvation of Li+ ions: Thermodynamics and energetic studies of Li+- $\left(\mathrm{H}_{2} \mathrm{O}\right)$ $\mathrm{n}(\mathrm{n}=1-6)$ structures. J. Mol. Liq. 2017, 241, 595-602. [CrossRef]

48. Gomaa, E.A.; Tahoon, M.A. Ion association and solvation behavior of copper sulfate in binary aqueous-methanol mixtures at different temperatures. J. Mol. Liq. 2016, 214, 19-23. [CrossRef]

49. Behdani, F.N.; Rafsanjani, A.T.; Torab-Mostaedi, M.; Mohammadpour, S.M.A.K. Adsorption ability of oxidized multiwalled carbon nanotubes towards aqueous Ce (III) and Sm (III). Korean J. Chem. Eng. 2013, 30, 448-455. [CrossRef]

50. Wang, Y.; Katepalli, H.; Gu, T.; Hatton, T.A.; Wang, Y. Functionalized magnetic silica nanoparticles for highly efficient adsorption of Sm3+ from a dilute aqueous solution. Langmuir 2018, 34, 2674-2684. [CrossRef]

51. Li, J.; Gong, A.; Li, F.; Qiu, L.; Zhang, W.; Gao, G.; Liu, Y.; Li, J. Synthesis and characterization of magnetic mesoporous Fe ${ }_{3} \mathrm{O}_{4} @$ $\mathrm{mSiO}_{2}$-DODGA nanoparticles for adsorption of 16 rare earth elements. RSC Adv. 2018, 8, 39149-39161. [CrossRef]

52. Abdel-Magied, A.F.; Abdelhamid, H.N.; Ashour, R.M.; Zou, X.; Forsberg, K. Hierarchical porous zeolitic imidazolate frameworks nanoparticles for efficient adsorption of rare-earth elements. Microporous Mesoporous Mater. 2019, 278, 175-184. [CrossRef]

53. Gargari, J.E.; Kalal, H.S.; Shakeri, A.; Khanchi, A. Synthesis and characterization of Silica/polyvinyl imidazole/H2PO4-core-shell nanoparticles as recyclable adsorbent for efficient scavenging of Sm (III) and Dy (III) from water. J. Colloid Interface Sci. 2017, 505, 745-755. [CrossRef] [PubMed]

54. Oliveira, R.C.; Jouannin, C.; Guibal, E.; Garcia, O., Jr. Samarium (III) and praseodymium (III) biosorption on Sargassum sp.: Batch study. Process Biochem. 2011, 46, 736-744. [CrossRef]

55. Mahmoud, M.R.; Soliman, M.A.; Allan, K.F. Adsorption behavior of samarium (III) from aqueous solutions onto PAN@ SDS core-shell polymeric adsorbent. Radiochim. Acta 2015, 103, 443-456. [CrossRef]

56. Shirvani-Arani, S.; Ahmadi, S.J.; Bahrami-Samani, A.; Ghannadi-Maragheh, M. Synthesis of nano-pore samarium (III)-imprinted polymer for preconcentrative separation of samarium ions from other lanthanide ions via solid phase extraction. Anal. Chim. Acta 2008, 623, 82-88. [CrossRef] [PubMed]

57. Sharma, P.; Singh, G.; Tomar, R. Synthesis and characterization of an analogue of heulandite: Sorption applications for thorium (IV), europium (III), samarium (II) and iron (III) recovery from aqueous waste. J. Colloid Interface Sci. 2009, 332, 298-308. [CrossRef] 